\title{
Aproximaciones para el desarrollo de una bioética forestal a partir del caso peruano*
}

\author{
Rodrigo Severo Arce Rojas ${ }^{a}$
}

\begin{abstract}
Resumen: el presente artículo tiene como objetivo primario reflexionar sobre cómo la bioética puede dar luces para un desarrollo forestal más comprometido con la vida en general. El estudio se focaliza en el Perú; sin embargo, se toma en cuenta información bibliográfica especializada de otros países con bosques tropicales. Se concluye que, aunque hay importantes avances científicos en el conocimiento sobre los bosques tropicales y expectantes experiencias certificadas de manejo forestal, no existe suficiente certeza científica que garantice su sustentabilidad ecológica. Lo anterior es producto tanto de la propia complejidad ecológica de los bosques tropicales, como de la complejidad sociocultural del sector forestal; lo que demanda aproximaciones que complementen los enfoques disciplinarios con perspectivas interdisciplinarias y transdisciplinarias. La realidad de los bosques es multidimensional, interdimensional, multiescalar y multitemporal; esta condición no logra ser captada por los planes de manejo forestal que descansan en el paradigma de una ciencia racional y empírica. A pesar de que hay valiosas medidas orientadas a la conservación de la biodiversidad forestal y previsiones para luchar contra la tala ilegal, el comercio y tráfico ilegal de la fauna silvestre, estas medidas para reducir la ilegalidad aún no son suficientes. A la fecha no existe una orientación específica sobre el respeto a la vida en el bosque en todas sus manifestaciones; además, los intentos que buscan la conservación de las especies de flora y fauna son desarticulados.
\end{abstract}

Palabras clave: amazonia; biodiversidad; bosque; silvicultura; ética; pensamiento

Recibido: 01 de febrero de 2020 Aceptado: 26 de mayo de 2020

Disponible en línea: 15 de septiembre de 2020

Cómo citar: Arce Rojas RS. Aproximaciones para el desarrollo de una bioética forestal a partir del caso peruano. Rev. latinoam. bioet [Internet]. 15 de septiembre de 2020; 20(1). Disponible en: https:// doi.org/10.18359/rlbi.4536

* Artículo de reflexión.

a Doctor en Pensamiento Complejo por la Multiversidad Mundo Real Edgar Morin de México. Profesor de Ecología Antropológica en la Maestría de Ecología y Gestión Ambiental de la Escuela de Posgrado en la Universidad Ricardo Palma, Lima, Perú. Correo electrónico: rodrigo.arce@urp.edu.pe ORCID 


\section{Approaches to developing a forest bioethics from the Peruvian case}

Abstract: the main objective of this article is to reflect on how bioethics can shed light on forest development that is more committed to life in general. The study focuses on Peru; however, specialized bibliographic information from other countries with tropical forests is considered. It is concluded that, although there are important scientific advances in knowledge about tropical forests and expectant certified experiences in forest management, there is not enough scientific certainty to guarantee their ecological sustainability. This is a product of both the ecological complexity of tropical forests and the socio-cultural complexity of the forest sector; which demands approaches that complement disciplinary approaches with interdisciplinary and transdisciplinary perspectives. The reality of forests is multidimensional, interdimensional, multiscale and multitemporal; this condition cannot be grasped by forest management plans that lie on the paradigm of a rational and empirical science. Although there are valuable measures aimed at conserving forest biodiversity and provisions to combat illegal logging, illegal trade and trafficking of wildlife, these measures to reduce illegality are still not enough. To the date there is no specific guidance on respect to forest life in all its manifestations, and in addition to that, attempts seeking to conserve the species of flora and fauna are disarticulated.

Keywords: Amazon region; biodiversity; forest; silviculture; ethics; thought

\section{Aproximações para o desenvolvimento de uma bioética florestal a partir do caso peruano}

Resumo: o objetivo principal deste estudo é refletir sobre como a bioética pode guiar um desenvolvimento florestal mais comprometido com a vida em geral. O estudo está focado no Peru; contudo, é considerada informação bibliográfica especializada de outros países com florestas tropicais. Concluise que, embora haja importantes avanços científicos no conhecimento sobre as florestas tropicais e esperadas experiências certificadas de gestão florestal, não existe suficiente certeza científica que garanta sua sustentabilidade ecológica. Isso é produto tanto da própria complexidade ecológica das florestas tropicais quanto da complexidade sociocultural do setor florestal, o que demanda aproximações que complementem as abordagens disciplinares com perspectivas inter e transdisciplinares. A realidade das florestas é multi e interdimensional, multiescalar e multitemporal. Essa condição não consegue ser captada pelos planejamentos de gestão florestal que se baseiam no paradigma de uma ciência racional e empírica. Apesar de haver valiosas medidas orientadas à conservação da biodiversidade florestal e previsões para lutar contra o desflorestamento ilegal, o comércio e o tráfico ilegal da fauna silvestre, as medidas para reduzir a ilegalidade ainda não são suficientes. Até o momento não existe uma orientação específica sobre o respeito à vida na floresta em todas as suas manifestações; além disso, as tentativas da conservação das espécies de flora e fauna são desarticuladas.

Palavras-chave: Amazônia; biodiversidade; floresta; silvicultura; ética; pensamento 


\section{Introducción}

En la actualidad, los problemas de frontera de la humanidad son la deforestación, la tala ilegal, la pérdida de la diversidad biológica, el cambio climático, la propagación de las pandemias asociadas a la destrucción de la naturaleza, entre otros. Frente a este panorama, es necesario revisar la forma en que el ser humano se relaciona con la naturaleza, teniendo en cuenta que las consecuencias sobre la vida en general han sido dramáticas. Pese a las intenciones de dar respuestas institucionales a estos fenómenos, el esquema fundamental de la economía cosifica a la naturaleza; los intentos de enverdecimiento de los modelos de desarrollo todavía se inscriben en el marco de una sustentabilidad débil. Se requiere, por tanto, pasar de una concepción antropocéntrica a concepciones más biocéntricas y ecocéntricas.

El presente artículo tiene como objetivo primario reflexionar sobre cómo la bioética puede dar luces para un desarrollo forestal más comprometido con la vida en general. De esta manera, se busca dar pistas para el fortalecimiento de políticas y prácticas forestales orientadas a la celebración y respeto hacia todas las formas de vida en los bosques.

Para cumplir el cometido del artículo se desarrolla el siguiente esquema argumentativo: en primer lugar, se revisan brevemente las etapas de la historia forestal mundial que han incidido en la historia forestal peruana; en segundo lugar, se abordan los paradigmas hegemónicos de las ciencias forestales y sus líneas de trabajo; en tercer lugar, los alcances del manejo forestal, y en cuarto lugar, la ética y la bioética forestal. Finalmente, se extraen las conclusiones a partir de una interpretación integrada. Pese a que se toma como referencia el caso peruano, la revisión bibliográfica es más amplia y se aspira a que contribuya al debate en el sector forestal latinoamericano.

\section{Resultados}

\section{Breve historia de las ciencias forestales}

Como lo indican Zapata y Peña (1), a lo largo de la historia, el ser humano ha utilizado los bosques como fuente de alimento, medicina, energía calórica, insumo para la construcción de viviendas, elaboración de armas, entre otros usos. El problema no radica en el uso de los recursos forestales, sino en buscar una forma de aprovechamiento que permita la conservación de sus capacidades de resiliencia, adaptación y evolución. De no tomar en cuenta estas consideraciones, la intervención humana podría terminar en procesos de alteración, degradación o conversión de bosques a otros usos de la tierra. Es necesario destacar que los bosques tropicales son ecosistemas naturales altamente complejos y frágiles que albergan la vida en todas sus manifestaciones, por ello, es pertinente hablar de una ética forestal.

Las ciencias forestales surgieron en el contexto del incipiente capitalismo europeo caracterizado por el desarrollo industrial, el cual hacía uso intensivo de los bosques tanto para el abastecimiento de leña, carbón y madera como para la ampliación de la frontera agrícola. La necesidad de que los bosques ofrezcan permanentemente volúmenes comerciales de madera llevó a la formulación del concepto de rendimientos sostenidos, que más adelante contribuyó a la concepción del desarrollo sostenible (2).

En el desarrollo histórico de las ciencias forestales europeas se reconocen varias etapas: explotación, regulación, manejo forestal, manejo forestal sostenible; así como la valoración del bosque por sus múltiples usos y su diversidad de actores, perspectiva que va más allá de la producción de artículos forestales maderables, tal como lo refiere Kimmins (3). Estas etapas también son aplicables a las ciencias forestales de los Estados Unidos y se han trasladado al caso peruano. Aunque en el Perú existe un proceso secuencial de las etapas señaladas, es necesario anotar que actualmente conviven prácticas de explotación, manejo forestal y manejo forestal sostenible con manifestaciones de extracción ilegal de madera y con una insuficiente aplicación de los planes de manejo forestal. De otro lado, actualmente se cuenta con un millón de hectáreas reconocidas por esquemas de certificación forestal independiente. La valoración de los múltiples usos de los bosques que trascienden enfoques de producción maderera están presentes especialmente 
en el sector de la conservación de bosques; sin embargo, no del todo en el sector que se autodenomina como productivo. Gracias al reconocimiento que han hecho las organizaciones internacionales, COmo FAO, PNUD, PNUMA, TCA, BID y el Banco Mundial, del valor estratégico de los bosques tropicales peruanos por su gran diversidad biológica, la contribución en la captura de carbono para hacer frente al cambio climático y la valoración en su rol en la provisión de agua dulce y la regulación climática a nivel global, cada vez son más tomadas en cuenta.

\section{El origen del paradigma forestal hegemónico}

De la concepción cartesiana se hereda el paradigma dominante que considera la separación entre el ser humano y los bosques. Estos últimos vistos como objeto de explotación para la satisfacción de las necesidades humanas; sin embargo, no siempre fue así. Como lo señala Hageneder (4), en Europa hay una tradición de estrecha interrelación del ser humano con los bosques, la cual tiene equivalencias con la riqueza cultural existente entre los indígenas amazónicos y su entorno natural, con sus particulares especificidades.

Influidas por la lógica de la ciencia positivista, surgieron las ciencias forestales, caracterizadas por ser disyuntivas, reductivas, lineales y deterministas. Como ciencia racional, empírica y objetiva, desestimó la ética, la estética y los conocimientos ancestrales. Aún así, no niega la irrupción de importantes corrientes de reencuentro del ser humano con los bosques, por ejemplo, las propuestas de Muir y de Leopold (la Ética de la Tierra) en los Estados Unidos referidas por Rozzi (5) y Rodríguez (6). Estas corrientes sobre el respeto a los bosques calaron más en el sector de su conservación en las Áreas Naturales Protegidas (ANP), que en el campo del aprovechamiento forestal. Una propuesta intermedia fue la de Glifford Pinchot en los Estados Unidos que hablaba de la "explotación sustentable", basada en la ciencia y la eficiencia, pero aún bajo la lógica de dominio humano sobre la naturaleza, como lo anotan Klier ET AL. (7).

Según Verjans (8), ante las críticas de los consumidores europeos sobre la falta de garantías del manejo sostenible de la comercialización de la madera procedente de los bosques tropicales, surgió el concepto de Certificación Forestal Voluntaria, bajo los principios del Concejo de Administración Forestal (FSC, por sus siglas en inglés). Se formularon criterios e indicadores que buscaban garantizar que los bosques certificados se manejaran bajo una perspectiva sustentable, tomando en cuenta dimensiones ambientales, sociales y económicas. Por su parte, los Estados de países tropicales también generaron principios y criterios sobre un buen manejo forestal (indicadores de Tarapoto, por ejemplo) como documenta Oliva (9). Otras medidas fueron: el requerimiento de planes de manejo forestal, la trazabilidad del origen legal de la madera, entre otras.

Aun cuando se han incorporado medidas para asegurar la sustentabilidad en el manejo de los bosques, su dimensión prioritaria sigue siendo la económica, enmarcada en una lógica capitalista. Esto se puede entrever en el lenguaje que se usa popularmente en la actividad forestal, pues que se sigue hablando de recursos forestales, de capital natural, de valoración económica de los servicios ecosistémicos, mercado de carbono, entre otros aspectos que dan cuenta de la lógica que está detrás de las actividades forestales, como aluden Toro y Martín (10).

Por ejemplo, en el Taller Regional Latinoamericano sobre Criterios e Indicadores (C\&I) para el Manejo Forestal Sostenible desarrollado en Tarapoto, se menciona:

los C\&I son vistos como un paso previo para la certificación. Si bien la certificación forestal puede generar beneficios desde una perspectiva social y ambiental, aparentemente no se constituye necesariamente en una ventaja competitiva y, por lo tanto, se considera como un esfuerzo costoso, demorado y que podría incluso poner en riesgo las inversiones desarrolladas (11, p. XX).

Es indudable que hay una fuerte motivación económica en el aprovechamiento de los bienes y servicios de los bosques. Como lo advierten Domínguez ET AL. (12) el problema está cuando todo el foco de atención se reduce a fines económicos, aunque se invoque la atención a consideraciones sociales y ambientales. 
La solución que ha generado la institucionalidad peruana para el desarrollo forestal descansa en dos premisas básicas: la primera consiste en que lo que carece de precio no se conserva y la segunda, que la propiedad privada es garantía de que existe un titular interesado en conservarlo y que el Estado puede dialogar y aplicar la fuerza de la ley con un titular claramente identificado. Como lo menciona Dourojeanni (13), bajo esta lógica, en el Perú se ha delegado el manejo forestal al sector privado.

\section{Las orientaciones del sector forestal}

Las ciencias forestales se desarrollaron en tres orientaciones básicas que aún se mantienen: manejo de bosques, conservación de bosques e industrias forestales. Aunque en teoría deberían haber formado un único cuerpo teórico para su desarrollo en la práctica, esta cohesión no se ha alcanzado por las diferentes perspectivas dominantes en cada una de las corrientes.

Así, el manejo de bosques y las industrias forestales se ha considerado como corrientes productivistas, mientras que la corriente de conservación de bosques se ha tipificado como conservacionista, como lo refieren Pacheco ET AL. (14). Sin embargo, no se ha logrado una integración entre el manejo de bosques y las industrias forestales y cada rama ha tenido su propio desarrollo.

Según Pacheco ET AL. (14), una tercera perspectiva es la holística, la cual considera que los bosques no solo deben atender el crecimiento económico y la conservación, sino también la reducción de la pobreza. Esta perspectiva aún no incorpora la importancia de los valores culturales y espirituales propios de los pueblos indígenas amazónicos. Cabe resaltar que para algunos pueblos indígenas los bosques no son considerados recursos sino entes vivientes.

\section{El propósito de las ciencias forestales}

La razón de ser de las ciencias forestales está orientada a la conservación y el aprovechamiento sostenible de los bosques. Inicialmente, la palabra conservación tenía la connotación de la gestión de uso de la biosfera que implicaba el uso (saber usar) y la preservación (saber proteger), como se desprende de la Unión Internacional de Conservación de la Naturaleza (UICN) (15). Esta formulación también aplicaba a los bosques, por tanto, se podría hablar de manera genérica sobre la conservación de los bosques comprendiendo tanto la dimensión de uso o aprovechamiento sostenible como la dimensión de conservación con especial énfasis en las ANP.

La confusión de atribuir el carácter proteccionista a la conservación obligó, en el caso de los bosques, el uso de la fórmula "conservación de bosques" y "aprovechamiento de bosques". Un problema con esta forma de dividir las ciencias forestales reside en que el aprovechamiento de bosques se asoció a una actividad productiva y económica, y aunque nunca se disoció del concepto de conservación, en la práctica quedó subordinada a la rentabilidad económica. Cabe resaltar que "el manejo forestal se gestó principalmente tomando como referencia la producción maderera de gran escala", como lo anotan Pacheco ET AL. (14).

De Camino (16) considera que la discusión entre conservacionistas y forestales productivistas sobre si es posible o no hacer manejo forestal sostenible es absurda. Desde una perspectiva de paisajes forestales sostenibles, la producción y la conservación se conciben de manera integrada, como lo describe el Programa Nacional de Conservación de Bosques para la Mitigación del Cambio Climático (PNCB) y el Servicio Nacional Forestal y de Fauna Silvestre (SERFor) (17). Por tanto, los profesionales forestales tienen el compromiso de intensificar la producción y a la vez proteger la biodiversidad forestal $(18,19)$.

El concepto de conservación de la naturaleza, en el que se inscribe la conservación de los bosques, estaba asociado en un principio al desarrollo sostenible, pero con la imposición de la economía liberal de las últimas décadas se ha ido perfilando un cariz economicista. La importancia de conservación de la naturaleza se sustenta a partir de las leyes del mercado. Asimismo, se incluyó el concepto de valoración de los servicios ambientales y los mecanismos de pago por los servicios ambientales, y se usaron criterios económicos para 
sustentar la importancia de la conservación estatal de áreas naturales protegidas para recibir mayor presupuesto público. De esta manera, las ciencias forestales participan ofreciendo las bases técnicas y científicas para fortalecer la conservación de la naturaleza.

El hecho de que se haya atribuido a la conservación de la naturaleza el carácter fundamentalmente proteccionista y a la silvicultura una orientación productivista ha tenido repercusiones. En teoría, la silvicultura debe descansar en sólidas bases ecológicas; sin embargo, en la práctica no se da necesariamente así. Aunque se cuenta con muchos avances sobre silvicultura tropical, el hecho de que los bosques tropicales sean de alta complejidad provoca un desconocimiento profundo de su dinámica, sus interrelaciones y las peculiaridades biológicas propias de las especies. Por tanto, para que haya una mejor sustentación técnica de las intervenciones silviculturales se requiere rigurosa ciencia (20), sin subestimar los aportes de los conocimientos tradicionales y saberes ancestrales sobre los bosques.

Una de las formas de responder a la complejidad ecológica, social, económica y cultural de los bosques tropicales es el manejo forestal adaptativo, como lo indica la Organización de las Naciones Unidas para la Alimentación y la Agricultura (FAO, por sus siglas en inglés) (21). El manejo forestal adaptativo busca que las consideraciones sociales, ambientales y económicas se ajusten al contexto local. Sin embargo, los Estados tienen diferentes grados de exigencia sobre las consideraciones ecológicas y cuando prima el criterio de acceso a los recursos forestales sobre la sustentabilidad, entonces los aspectos ecológicos y silviculturales del manejo forestal se flexibilizan. Además, el manejo forestal sostenible no es producto únicamente de consideraciones técnicas, sino de todo el complejo de la realidad que desde la administración pública se gestiona sectorialmente y con contradicciones entre lo que se llama desarrollo y conservación.

Desde una perspectiva de conservación de la naturaleza, existe la discusión de si el foco debe estar en los individuos, especies o ecosistemas, como lo menciona Esteve (18). Dependiendo del enfoque adoptado, es posible que la prioridad de la conservación de una especie pueda afectar a otras especies "que no son deseables". En el caso de la conservación de la naturaleza, se usa el criterio de representatividad ecológica en tanto se argumenta que no es posible conservarlo todo.

En el sector forestal existe la conciencia de la necesidad de ampliar la mirada del aprovechamiento forestal, concentrada en productos forestales madereros a una perspectiva más sistémica y con consideraciones sociales; sin embargo, no es una posición generalizada, según Castañeda y Sabogal (19).

\section{El concepto y los alcances del manejo forestal}

El manejo forestal en esencia implica simplificación del ecosistema, es decir, privilegiar especies de interés comercial consideradas deseables e incluso eliminar especies consideradas como no deseables. Aquí ya se evidencia una primera implicancia sobre la vida, pues son los intereses humanos los que deciden cuál es el valor de una especie, independientemente de sus valores intrínsecos. Los esquemas de valoración de los servicios ecosistémicos, aun cuando incorporan aspectos culturales, siguen enmarcados en una lógica de economía de mercado.

\section{El manejo forestal por sí solo no basta}

Desde la perspectiva institucional, el manejo de bosques con titulares reconocidos y fiscalizados es la mejor manera de conservar los bosques. Como lo demuestran los datos (13), cuando un bosque no tiene un titular de derecho, queda expuesto a la deforestación y la tala ilegal. Se parte del supuesto de que el concesionario forestal cuida sus bosques. Bajo esta premisa, en el Perú se promueven nuevas áreas de concesiones para la promoción de inversiones forestales (13). De nuevo, surge la pregunta sobre si la privatización del manejo forestal es la mejor forma de garantizar la conservación de los bosques.

Es importante considerar que el manejo forestal sostenible no obedece a una correlación lineal entre aplicación de las leyes y prescripciones 
contempladas en el plan de manejo forestal. En cambio, responde a un complejo donde intervienen personas, estructuras, sistemas, flujos, dinámicas y procesos, tanto al interior de los bosques como en el entorno. Todo depende del real compromiso que pueda tener el Estado y los propios manejadores de bosques o los titulares para garantizar la conservación de los bosques.

Hay dos maneras distintas de enmarcar el desarrollo forestal: por un lado, en el desarrollo sostenible basado en la preminencia del capitalismo neoliberal; por otro lado, en el Biodesarrollo, un concepto que sí reconoce la centralidad de la vida en todas sus manifestaciones. Este segundo marco comprende un desarrollo forestal respetuoso de la vida humana y no humana.

\section{Los impactos para la vida del manejo forestal}

Aun cuando en los principios y criterios del manejo forestal, tanto legales como voluntarios, hay consideraciones para asegurar el respeto de la fauna, en la práctica siempre hay impactos directos e indirectos que las afectan. En este contexto reciben atención especies visibles por su tamaño, belleza (relativa) o importancia ecológica en detrimento de otras especies que no son valoradas y, por lo tanto, son consideradas prescindibles.

Si partimos del supuesto de que se deben respetar todas las manifestaciones de vida en los bosques, no habría necesidad de intervenir y se anularía el manejo forestal. Con todas las implicancias que eso podría tener sobre la economía y la vida de las personas que habitan en y subsisten de los bosques, se hace prioritario pensar sobre lo que es más apropiado para el bienestar de la gente y para la integralidad ecológica de los bosques. Si no están aseguradas las condiciones estructurales para garantizar la sustentabilidad ecológica de los bosques, es necesario explorar otras opciones.

Una posibilidad de intervención del bosque consiste en que los impactos sean los mínimos posibles, de tal manera que se asegure la capacidad adaptativa y evolutiva de los bosques. Respecto a la extracción de la madera, surgen preguntas como: ¿son medidas suficientes la técnica de tala de impacto reducido para el mayor respeto a la vida, tomar en cuenta los diámetros mínimos de corta y cumplir un ciclo de corte de 20 o 40 años para bosques con especies cuya maduración es centenaria?, ¿se ha tomado en cuenta la ecología de las especies madereras extraídas?, ¿existe la cantidad necesaria de bases silviculturales de bosques tropicales? (22). Al respecto, el Movimiento Mundial por los Bosques Tropicales (23) considera que la tala selectiva no es una garantía efectiva para la conservación de los bosques. Jiménez y Mantilla (24) mencionan que la tala selectiva tiene un efecto significativo sobre las comunidades de mamíferos y en particular quirópteros (p. 105). Asimismo, la literatura científica revisada por Armenteras ET AL. (25) indica que la tala selectiva también es uno de los factores de degradación de bosques. Pérez et al (26) consideran que los bosques tropicales son muy vulnerables al cambio climático y que las perturbaciones pueden causar pérdida de biodiversidad por la modificación de la estructura etárea y su incidencia en la estructura del bosque y la composición de especies.

Teniendo en cuenta las medidas frente al cambio climático y que los bosques naturales tropicales son una fuente de recursos estratégicos para la alimentación y salud y tienen un rol clave en los ciclos hidrológicos globales, surge una discusión sobre el destino de estos bosques y se reconocen tres orientaciones. La primera orientación refiere a la intensificación del aprovechamiento forestal fundamentalmente con fines de producción maderera; la segunda ve a la Amazonía como un área de expansión de actividades agroindustriales a gran escala para la producción de alimentos de interés global (palma aceitera, soya); y la tercera considera a la Amazonía como la nueva frontera para la explotación de sus ingentes recursos mineros y petroleros. Esta última orientación es la elegida por los proyectos de infraestructura vial y de energía.

Una opción alternativa que no ha recibido la suficiente atención alude a una perspectiva como fuente de recursos para la biotecnología con fines de alimentación, salud y belleza. También es posible cambiar un esquema de materialidad por uno que valore el conocimiento (científico y local) con el apoyo de la tecnología. Adicionalmente, 
es importante revisar opciones que consideren a los bosques como laboratorios naturales para el conocimiento científico y fuentes para tecnologías inspiradas en la naturaleza (Biomímesis).

De Groot ET AL., citado por Dourojeanni (13) señala que cualquier análisis económico integral demuestra que el bosque natural tropical es más valioso por sus servicios ambientales que como productor de madera y otros bienes. Asimismo, es más importante, pensando en el futuro de cualquier nación, tener bosques naturales que explotarlos $(13,27)$. Por tanto, se debe reflexionar sobre las implicancias de apostar fundamentalmente a las concesiones madereras. Esto requiere un diálogo fecundo, transparente y estratégico para definir cuál es la alternativa más sensata sobre el destino de los bosques naturales peruanos.

\section{Los desafíos del manejo forestal}

Los desafíos para el ansiado manejo forestal sostenible (MFs) son aún significativos. Por ejemplo, en el 2006 se habló de un aumento considerable en la intensidad de extracción de madera en la Amazonia; esto no implicó una mejora en la calidad de las operaciones, como tampoco en las condiciones para los trabajadores y sus familias. En la mayoría de los casos, luego del aprovechamiento, el bosque era abandonado sin ningún manejo y quedaba a la espera de la próxima cosecha, como lo señalan Castañeda y Sabogal (19).

Según Dourojeanni (13), en el 2019 se evidencian las deficiencias de los planes de manejo forestal y las debilidades en su implementación. Aunque ya existen empresas forestales certificadas que cumplen criterios e indicadores relativos a aspectos ambientales, sociales y económicos, incluyendo operaciones forestales comunitarias, un sector de la actividad forestal todavía considera a los planes de manejo como requisito administrativo y no como una herramienta de gestión.

De Camino (16) señala que, en caso de existir críticas sobre el concepto de manejo forestal sostenible, habría que hablar de buen manejo forestal, o incluso de aprovechamiento de bajo impacto. Con el fin de reconocer el manejo forestal sostenible como un ideal, otros involucrados en el sector forestal prefieren hablar de manejo forestal responsable. Cabe señalar que no se trata únicamente de un tema semántico, sino del genuino compromiso por la vida en el bosque en todas sus manifestaciones.

Según Castañeda y Sabogal (19), implementar un manejo forestal sostenible tiene un costo que no todos están dispuestos a asumir. ¿Significa, entonces, que el acceso a los bosques solo debería estar disponible para corporaciones con capacidades solventes de inversión? Todo depende del paradigma usado por los actores para acercarse al bosque y del tipo de preguntas que se hagan. Teniendo en cuenta lo anterior, ¿cuál es la mejor alternativa de interacción con los bosques que respete profundamente la vida y a la vez pueda generar opciones para una diversidad de actores? Este tipo de cuestionamiento es más coherente con la perspectiva del Biodesarrollo porque considera el bienestar del bosque y de las personas. Actualmente la economía se orienta a la desmaterialización y la localización. Aquí cobran sentido los valores ecológicos, culturales y espirituales de los bosques; lo que implica una forestería basada en las posibilidades que ofrecen las ciencias y tecnologías actuales.

Darle un mayor valor al bosque natural no implica necesariamente incrementar el número de productos a extraer, volúmenes de producción o especies de aprovechamiento. Significa, en primer lugar, reconocer el valor intrínseco de los ecosistemas forestales con la plenitud de sus riquezas de biodiversidad forestal, como lo refiere la Secretaría del Convenio sobre la Diversidad Biológica (SCDB) (28); y, en segundo lugar, buscar la opción más sensata que implique la menor intervención invasiva posible, pero a la vez rinda los mejores beneficios para la diversidad de actores involucrados. Al respecto, la SCDB (28) menciona lo siguiente:

Los bosques están desapareciendo, en parte debido a que no se han valorado lo suficiente, y nuestra economía de mercado no toma en cuenta los servicios ecosistémicos que proporcionan los bosques en buen estado. Para dejar de perder este tesoro viviente del planeta, debemos entender y apreciar su amplia gama de valores, así como su importancia para el bienestar humano y el desarrollo (p. 8).

De ahí la importancia de amplios procesos participativos de diálogo. Desde esta perspectiva se 
entiende la propuesta de Dourojeanni (13): los bosques naturales tendrán mejor destino si se dedican a bienes y servicios ambientales y, por otro lado, si la madera, cuya demanda seguirá siendo creciente, proceda de plantaciones donde se respete la biodiversidad forestal y la integridad de las cuencas hidrológicas. Cabe resaltar que la promoción de plantaciones forestales deberá seguir las consideraciones de Bioética forestal.

\section{Ética ambiental y ética forestal}

La ética medioambiental es una ética aplicada que reflexiona sobre los fundamentos de los deberes y responsabilidades del ser humano con la naturaleza, los seres vivos y las generaciones futuras (29, 30 ). Se puede entonces afirmar que una ética forestal aborda las relaciones entre el ser humano y la totalidad de los seres vivos asociados al bosque.

El tema de la ética forestal, como se ha señalado anteriormente, no es ajeno al desarrollo de las ciencias forestales; no obstante, ha quedado rezagado en el campo de la conservación. Aunque no se le mencione explícitamente, el campo productivo es incompatible con una ética ecológica. Desde una perspectiva economicista, "salvo el crecimiento, todo es ilusión”. En este proceso, la ética forestal es considerada impertinente para una actividad de carácter económico. De hecho, es el criterio usado para exigir que el subsector forestal se ubique en un sector productivo de la administración pública.

Macqueen (31) reconoce que existen múltiples grupos interesados en los bosques, cada uno con su propia ética, es decir, derechos y valores propios. Una solución planteada es la apelación ética como un proceso orientado a alcanzar acuerdos, lo que implica reconocer una ética forestal común, las diversas aspiraciones y un fecundo diálogo democrático. Hacia esta misma dirección apunta la Ética Convergente, propuesta por Maliandi y Thüer, citada por Landínez,

como una valiosa herramienta en la resolución de este tipo de problemas ambientales, dado que considera las estructuras conflictivas: diacrónica y sincrónica; la bidimensionalidad de la razón: fundamentación y crítica, así como los principios biotecnoéticos: precaución, exploración, no discriminación y respeto a la diversidad genética (32, p. XX).

\section{La ética en el marco político y legal peruano}

El objetivo del Ministerio del Ambiente (MINAM) es la conservación del ambiente, de modo que propicie y asegure el uso sostenible, responsable, racional y ético de los recursos naturales y del medio que los sustenta. Asimismo, pretende contribuir al desarrollo integral social, económico y cultural de la persona humana, en permanente armonía con su entorno, y así asegurar a las generaciones presentes y futuras el derecho a gozar de un ambiente equilibrado y adecuado para el desarrollo de la vida (33).

El objetivo de la Política Nacional Forestal y de Fauna Silvestre (PNFFS) es contribuir al desarrollo sostenible del país a través de una adecuada gestión del Patrimonio Forestal y de Fauna Silvestre de la Nación. Esta gestión debe asegurar el aprovechamiento sostenible, conservación, protección e incremento para la provisión de bienes y servicios de los ecosistemas forestales, otros ecosistemas de vegetación silvestre y de la fauna silvestre, en armonía con el interés social, cultural, económico y ambiental de la nación, como lo refiere SERFOR (34).

La Ley Orgánica para el aprovechamiento sostenible de los recursos naturales - Ley No 26821 tiene como objetivo promover y regular el aprovechamiento sostenible de los recursos naturales, renovables y no renovables. Asimismo, establecer un marco adecuado para el fomento a la inversión, procurando un equilibrio dinámico entre el crecimiento económico, la conservación de los recursos naturales y del ambiente y el desarrollo integral de la persona humana (Art. 2). Desde esta perspectiva, se consideran recursos naturales a todo componente de la naturaleza susceptible de ser aprovechado por el ser humano para la satisfacción de sus necesidades y que tenga un valor actual o potencial en el mercado (Art. 3).

Según SERFOR (35), la Ley Forestal y de Fauna Silvestre - $\mathrm{N}^{\circ} 29763$ recoge el concepto de recursos naturales de la Ley No 26821 y especifica que son recursos forestales, independientemente de su ubicación en el territorio nacional: a) los bosques naturales; b) las plantaciones forestales; c) las tierras cuya capacidad de uso mayor es forestal y para 
protección, con o sin cobertura arbórea, y d) los demás componentes silvestres de la flora terrestre y acuática emergente, incluyendo su diversidad genética (Art. 5).

La referencia a la palabra ética en los documentos es casi inexistente si revisamos instrumentos de política y normatividad ambiental y forestal, tales como: la Estrategia Nacional ante el Cambio Climático, la Estrategia Nacional sobre Bosques y Cambio Climático (ENBCC), la Estrategia Nacional sobre Diversidad Biológica al 2021, la Estrategia Nacional para Reducir el Tráfico Ilegal de Fauna Silvestre en el Perú en el periodo 2017 - 2027 y su Plan de Acción 2017 - 2022; la Política Nacional del Ambiente y la Política Nacional Forestal y de Fauna Silvestre (PNFFs). Lo mismo sucede al revisar el compendio de legislación ambiental en el Perú en sus volúmenes I y II (que comprende hasta el 2010). Según Arce (36), en el compendio legislativo sobre cambio climático en el Perú, actualizado el 26 de noviembre de 2014, en el tomo I no hay ninguna referencia a la palabra ética y en el tomo II aparece una.

\section{La bioética forestal}

La perspectiva de Biodesarrollo con orientación al respeto a la vida da pie a una bioética forestal, entendida como una ética aplicada que estudia las implicancias morales de la relación entre los seres humanos y los bosques. Asimismo, no se queda únicamente en una moral humana, sino que amplía la comunidad moral a todos los seres vivos no humanos como plantas y animales. Como señalan Brand ET AL. (37), más allá del PIв hay vida.

Cabe señalar que la bioética forestal no es antihumana y tampoco plantea un biocentrismo fundamentalista. Por lo tanto, no se opone a la intervención humana sobre los bosques y, en cambio, exige una intervención responsable y cuidadosa para que el ser humano satisfaga sus necesidades. Como señala Castro (38), la perspectiva bioética implica hacer lo que corresponda en el marco del respeto a la vida, en tanto el interés humano no es lo único que cuenta. El concepto de ética se inscribe en una forma de relacionarse con el otro, incluyendo a la alteridad de plantas y animales, en un espacio y tiempo determinado (ética como morada) $(12,39,40)$.
En el marco de la buena gobernanza forestal, las consideraciones de la bioética pueden ayudar a la sociedad y a los Estados a tomar la mejor decisión sobre el destino de los bosques, considerando no solo los intereses de los seres humanos, sino también de una comunidad moral ampliada a las plantas y animales, como lo señala Cálix (41). En este orden de ideas, la bioética garantiza una mejor relación entre el ser humano y la naturaleza, como señala Machado (42).

Algunas de las consideraciones de una bioética forestal se desprenden de las propuestas literales de Pérez (43): a) una ética de la naturaleza amplía los límites de la comunidad humana, para incluir al suelo, el agua, las plantas y los animales; b) una ética ecológica requiere una meditación crítica acerca de las consecuencias de las acciones y estilos de vida humanos; c) la solución de la crisis ambiental requiere nuevos valores, sistemas sociales y estructuras políticas; d) la ética humana no debe separarse de los hechos biológicos; e) para el desarrollo pleno de un organismo, es esencial que este se encuentre bien en el ambiente donde está evolucionando; f) el avance económico no debe ser determinante único de la utilización ambiental, y g) toda especie tiene derecho a una supervivencia continuada en el ambiente donde vive.

\section{Avances forestales sobre el respeto a la vida}

El aprovechamiento de los bosques ha incorporado gradualmente importantes elementos para garantizar la sustentabilidad ecológica desde la administración pública y las iniciativas voluntarias de certificación. Adicionalmente, se están tomando previsiones para demostrar el origen legal de la madera, tales como la trazabilidad apoyada por herramientas analógicas y tecnológicas. Frente a la complejidad de los bosques tropicales, cabe preguntarse por la efectividad de las previsiones para asegurar la sustentabilidad ecológica.

El reconocimiento de la complejidad forestal conduce indefectiblemente a acercamientos más interdisciplinarios y transdisciplinarios de los bosques, teniendo en cuenta las interacciones con la sociedad presente y futura, como indica Giménez (44). Desde esta perspectiva, cabe señalar cómo 
la Comisión Económica para América Latina y el Caribe (cepal) consideran la importancia de abordar aspectos de la economía ecológica y posiciones biocéntricas para enriquecer su pensamiento económico (12).

\section{Discusiones}

La bioética forestal significa una novedosa aproximación que cruza las actividades de conservación, aprovechamiento de los bosques y su restauración al tomar en cuenta la importancia de la vida en todas sus manifestaciones. Esto implica superar una concepción antropocéntrica derivada de la ontología disyuntiva que separa el ser humano de la naturaleza.

Al ampliar la atención y aceptación de la vida más allá del ser humano, se está hablando de las consideraciones éticas sobre la vida no humana, es decir, plantas y animales. Tradicionalmente, se ha legitimado la concepción de que la ética aplica exclusivamente a la vida humana en tanto ser con atributos que la separan de la naturaleza como la conciencia, la inteligencia, la cultura, entre otros. Sin embargo, las investigaciones más avanzadas sobre los animales demuestran que hay niveles de conciencia en especies animales como los grandes simios y aves $(45,46)$. Asimismo, se encuentran expresiones de inteligencia en las plantas $(47,48,49)$. La cultura se creía un rasgo diferenciador del ser humano frente a los animales, pero las investigaciones demuestran que algunos animales elaboran herramientas y existen evidencias de comportamiento socialmente aprendido (49).

Esta ampliación de la conciencia hacia otras expresiones de vida conlleva a prestar atención en el significado de la vida en general. Terminológicamente, la vida es difícil de definir desde la perspectiva de los biólogos, quienes se centran en algunas características como la capacidad de autoorganización y de reproducción. La vida es compleja y en ocasiones presenta situaciones borrosas, especies de difícil clasificación taxonómica, situaciones límite de expresiones de vida como los organismos extremófilos o presencia de fenómenos de latencia de vida que escapan a una temporalidad concebida tradicionalmente. También se verifican casos en que resulta complicado diferenciar la vida de la no vida (50). Estos fenómenos han sido puestos en evidencia por la biocomplejidad que remite a los conceptos de organización, función y sustancia (51).

Por las anteriores razones, resulta relevante poner en discusión el tema de la conciencia animal. Desde la perspectiva de Damasio, existen dos tipos de conciencia: la nuclear y la ampliada. La conciencia nuclear es la más básica y es propia de los seres vivos que advierten la presencia de sí mismos (52). Por su parte, la conciencia ampliada corresponde al ser humano. No obstante, aún está en debate el carácter de la conciencia animal. Lo mismo ocurre con la sintiencia animal que alude a la capacidad de sentir dolor, gozo o incomodidad. Existen diferentes valoraciones respecto al grado de sintiencia animal. Pero más allá de las posiciones que se puedan tomar respecto a la conciencia y sintiencia animal, es importante reconocer que las especies deben desplegar su potencial biótico, lo que implica extender con plenitud su naturaleza (53).

Desde la perspectiva de algunos pueblos indígenas amazónicos, los animales y las plantas también son considerados seres que pueden relacionarse con las personas. El carácter de lo vivo y lo sagrado se amplía incluso a otros componentes del territorio como las montañas y los ríos, denominados por Escobar como ontologías relacionales (54). Estas discusiones se traducen actualmente en el movimiento de los derechos de la naturaleza plasmada en la Constitución Política del Ecuador y que han inspirado los marcos legales en varios países.

Con todos estos antecedentes, se llega al tema de la bioética forestal. Existen referencias que documentan que el aprovechamiento forestal causa impactos positivos y negativos en la fauna. Adicionalmente, hay referencias sobre especies animales que son indiferentes a la intervención. No obstante, cabe destacar el carácter complejo de los bosques tropicales como ecosistemas, inclusive como socioecosistemas si se parte desde un enfoque biocultural.

El marco legal peruano se inscribe en la lógica de la ontología disyuntiva entre el ser humano y la naturaleza, por lo tanto, en una perspectiva utilitarista que considera a los bosques como fuente de 
recursos naturales sujetos a su aprovechamiento (o explotación). Aunque existen consideraciones de conservación de la fauna en las operaciones forestales, el enfoque predominante evidencia su tratamiento como recurso. No existe una referencia explícita a los valores intrínsecos de la vida.

De los aspectos señalados, se desprende la necesidad de superar visiones reduccionistas de desarrollo forestal que solo ven a los bosques como recursos forestales o capital natural desde una lógica de mercantilización de la naturaleza en un esquema orientado al crecimiento económico. La mirada que enfatiza de manera aislada a los bienes o servicios, no da cuenta de la complejidad de los bosques tropicales ni del papel de la cultura de los pueblos indígenas. Perspectivas administrativas sectoriales y abordajes disciplinarios en el aprovechamiento forestal son insuficientes para garantizar el respeto a la vida en todas sus manifestaciones.

El reconocimiento de la complejidad de los bosques nos conlleva a aplicar el enfoque de sistemas adaptativos complejos; una herramienta para la investigación procedente de las ciencias de la complejidad. Un sistema adaptativo complejo comprende un conjunto de elementos interrelacionados, interdependientes e interdefinibles. Estos sistemas presentan las propiedades de la autoorganización y las emergencias que son comportamientos que resultan de la interacción y que no son atribuibles a sus componentes de forma separada. Son sistemas no lineales y se encuentran alejados del equilibrio. Como sistemas anidados, presentan interrelaciones de mutua influencia hacia al interior y el entorno del sistema. Además, son sistemas descomponibles e irreversibles (55). De este marco teórico se deduce que las intervenciones de aprovechamiento forestal focalizados solo en algunos productos o servicios no responden a la complejidad del bosque tropical.

Aunque en la legislación peruana sobre bosques se encuentra el principio de enfoque sistémico, resulta complicada su implementación en tanto priman los enfoques sectoriales y disciplinarios. La débil capacidad de articulación es uno de los rasgos de la administración pública peruana. De ahí la necesidad de abordar la gestión de los bosques tropicales desde perspectivas interdisciplinarias y transdisciplinarias que resignifiquen las aproximaciones disciplinarias.

La perspectiva de la epistemología de una ciencia positivista es insuficiente para abordar el conocimiento de los bosques tropicales y el fenómeno de la vida. Por lo tanto, es pertinente ampliar otras miradas como las que proceden de las ciencias de la complejidad y la epistemología evolucionaria (56). En este contexto, se entiende la necesidad de las gestiones de los paisajes, de los socioecosistemas, territorial, biocultural, entre otras, ya que valoran el conocimiento y el respeto por la vida, así como los valores culturales desde una aproximación dialógica, recursiva e intercultural. Se requiere, por tanto, ampliar la concepción moral e incorporar el valor de la vida en todas sus manifestaciones.

Los bosques tropicales, con todas sus expresiones de vida interrelacionadas, cumplen un rol estratégico a nivel global en términos hidrológicos y climatológicos. La reciente constatación de la degradación de los ecosistemas naturales, la pérdida de biodiversidad y la fragmentación de hábitats está ocasionando que los virus se transmitan mediante vectores a otros animales silvestres o domésticos y que finalmente contagien al ser humano. Así, si la destrucción de la naturaleza esta relacionada con la generación de pandemias, la conservación de los ecosistemas es una garantía para que los virus se mantengan en su red de relaciones y por tanto se reduzca el riesgo de contagio humano. Esto invita a reflexionar sobre el modo en que el ser humano se ha relacionado con los bosques y exige la incorporación de dimensiones éticas (57).

\section{Conclusión}

Aunque hay importantes avances científicos en el conocimiento sobre los bosques tropicales y expectantes experiencias de manejo forestal, sobre todo las que están certificadas, no hay suficiente certeza científica que garantice la sustentabilidad ecológica del manejo forestal. Esto es producto tanto de la propia complejidad ecológica de los bosques tropicales, como de la complejidad sociocultural del sector forestal. De ahí que demande aproximaciones que complementen los enfoques disciplinarios con perspectivas interdisciplinariasy transdisciplinarias. La realidad multidimensional, 
interdimensional, multiescalar y multitemporal de los bosques no logra ser captada por los planes de manejo forestal que descansan en el paradigma de una ciencia racional y empírica.

A nivel social, la visión de los bosques ha evolucionado al hacer consideraciones más integrales que no residen exclusivamente en una perspectiva maderera y economicista. En el Perú todavía existe la lucha para que se institucionalice un manejo forestal sostenible, teniendo en cuenta que prima el paradigma de que los bosques naturales poseen ingentes recursos que deben ser explotados para atender las necesidades de productos maderables de una población que crece exponencialmente. La perspectiva de gestión de paisajes forestales sostenibles que integra producción y conservación tiene dificultades de arraigo por la sectorialización de la administración pública regida por cánones neoliberales.

Aunque hay valiosas medidas orientadas a la conservación de la biodiversidad forestal y previsiones para luchar contra la tala ilegal, el comercio y tráfico ilegal de la fauna silvestre, estas medidas para reducir la ilegalidad aún no son suficientes. A la fecha no existe una orientación específica por el respeto a la vida en el bosque en todas sus manifestaciones. Además, los intentos que buscan la conservación de las especies de flora y fauna son desarticulados.

Se requiere, por tanto, un amplio diálogo social que apele a una nueva ética forestal en la formulación de un acuerdo nacional que satisfaga las múltiples aspiraciones de los sectores y actores de la sociedad. Además, debe incluir los valores de la vida, los valores culturales y espirituales de los pueblos indígenas en un contexto donde hay una alta pérdida de diversidad biológica y retos a afrontar como el cambio climático y la erradicación de la pobreza. Todo esto en un contexto de gran desarrollo de la tecnociencia. Desde un marco de las alternativas al desarrollo, el valor estratégico debe abordar la bioética forestal para recuperar valores y sentidos.

\section{Referencias bibliográficas}

1. Zapata L, Peña L. La historia del bosque y su explotación en el pasado: evidencia arqueológica y etnográfica. Zainak [Internet]. 1998 [revisión 2020 febr. 26];17:87-99. Disponible en: https://core.ac.uk/download/pdf/11497405.pdf

2. Sanz G. Naturaleza y ciencias forestales en Alemania. Una aproximación a la historia de una tradición académica. Cuad. Soc. Esp. Cienc. For [Internet]. 2003 [revisión 2020 febr. 26];16: 161-166. Disponible en: DOI: https://doi.org/10.31167/csef.v0i16.9366

3. Kimmins JP. Balancing Act, Environmental issues in forestry. 2nd ed. Vancouver, Canada: UBC Press; 1999.

4. Hageneder F. El legado de los árboles. Historia, cultura y simbolismo. Santiago de Chile: Columba Ediciones; 2009. 213 p.

5. Rozzi R. De las ciencias ecológicas a la ética ambiental. Rev. chil. his. nat [Internet]. 2007 [revisión 2020 febr. 26];80(4):521-534. Disponible en: DoI: https://doi. org/10.4067/S0716-078X2007000400012

6. Rodríguez J. Conservación de la naturaleza: crítica a la estrategia contemporánea para la conservación de especies [tesis doctoral]. [Valencia]: Universitat de València; 2012. 511 p.

7. Klier G, Casalderrey C, Busan T, di Pasquo F. Conservación de la biodiversidad y sus vínculos utilitaristas: cercanías y distancias con Peter Singer y Gifford Pinchot. Rev. Metrov. Sustentabilidade [Internet]. 2017 [revisión 2020 febr. 26]; 7(3):63-81. Disponible en: http://www.revistaseletronicas.fmu.br/index.php/ rms/article/view/1462/html_2

8. Verjans JM. Interpretación de los principios y criterios del FSC en manejo forestal. Kurú [Internet]. 2011 [revisión 2020 febr. 26]; 8(21):13-16. Disponible en: https:// revistas.,tec.ac.cr/index.php/kuru/article/view/371

9. Oliva E. Evolución del manejo forestal sostenible. Rev. For. de Guatemala (3a Ed) [Internet]. 2019 jun. [revisión 2020 febr. 26]; 5-6. Disponible en: http://www. inab.gob.gt/documentos/seriedivulgativa/revistaforestaledicion3.pdf

10. Toro C, Martín F. Presentación. En: Alimonda H, Escobar A, Noguera A, ET AL. Ecología política latinoamericana: pensamiento crítico, diferencia latinoamericana y rearticulación epistémica. Ciudad Autónoma de Buenos Aires: CLACSO; México: Universidad Autónoma Metropolitana; Ciudad Autónoma de Buenos Aires: Ciccus. 2017. p. 13-20. 
11. Organización de las Naciones Unidas para la Alimentación y Agricultura (FAO, por sus siglas en inglés) Taller Regional Latinoamericano sobre Criterios e Indicadores para el Manejo Forestal Sostenible. Informe final. Tarapoto: FAO, por sus siglas en inglés; 2015.

12. Domínguez R, León M, Samaniego J, Sunkel O. Recursos naturales, medio ambiente y sostenibilidad: 70 años de pensamiento de la CEPAL. Santiago: Libros de la CEPAL; 2019.

13. Dourojeanni MJ. Esbozo de una nueva política forestal peruana. RFP [Internet] 2019 [revisión 2020 febr. 26]; 34(1):4-20. Disponible en: DoI: https://doi. org/10.21704/rfp.v34i1.1244

14. Pacheco P, Ibarra E, Cronkleton P, Amaral P. Políticas públicas que afectan el manejo forestal comunitario. En: Sabogal C, de Jong W/ Pokorny B, Louman B, editores. Manejo forestal comunitario en América Latina: experiencias, lecciones aprendidas y retos para el futuro. Bogor, Indonesia: Centro para la Investigación Forestal (CIFOR); 2008. p. 201-228. Disponible en: http:// www.infobosques.com/descargas/biblioteca/140.pdf

15. Unión Internacional para la Conservación de la $\mathrm{Na}$ turaleza (UICN). Estrategia Mundial para la Conservación: la conservación de los recursos vivos para el logro de un desarrollo sostenido. Gland: Programa de las Naciones Unidas para el Medio Ambiente (PNUMA), Fondo Mundial para la Naturaleza (wwF: por su sigla en inglés). 2018.

16. De Camino R. Cooperación forestal con Iberoamérica. Una visión desde el sur. En: Martínez de Anguita P, editor. Política Forestal y Cooperación Internacional. Connecticut: Organismo Autónomo de Parques Nacionales de España; 2012. p. 65-88.

17. Programa Nacional de Conservación de Bosques (РNCB) del Ministerio del Ambiente. Servicio Nacional Forestal y de Fauna Silvestre (SERFOR) del Ministerio de Agricultura y Riego. Estrategia Nacional sobre Bosques y Cambio Climático. Lima, Perú. 2016. Disponible en: http://www.minam.gob.pe/wp-content/ uploads/2016/07/ESTRATEGIA-NACIONAL-SOBRE-BOSQUES-Y-CAMBIO-CLIM\%C3\%81TICO-DECRETO-SUPREMO-007-2016-MINAM11.pdf

18. Esteve MA. Evolución de los paradigmas en conservación de la naturaleza desde una perspectiva ambiental. Rev. Eubacteria [Internet]. 2015 [revisión 2020 febr. 26];34:44-51. Disponible en: https://www.um.es/eubacteria/Ecologia_Eubacteria34.pdf

19. Castañeda F, Sabogal C. Manejo sostenible del bosque tropical en la cuenca amazónica Tendencias y perspectivas. Rec. Nat. y Amb [Internet]. 2006-2007 [revisión 2020 febr. 26]; 49-50:6-11. Disponible en: http://www.cifor.org/publications/pdf_files/articles/ ASabogal0701.pdf

20. Corporación Alemana para la Cooperación Internacional (GIZ, por su sigla en alemán). La certificación FSC en el Perú: avances y desafíos de las concesiones forestales maderables. Trujillo M. Lima: Programa Contribución a las Metas Ambientales del Perú (ProAmbiente II); 2018. Disponible en: https://cooperacionalemana.pe//GD/971/giz2018_es_Ambiente_Doc-trabajo-1-La-certificacion-FSC-en-Peru2.pdf

21. Organización de las Naciones Unidas para la Alimentación y la Agricultura ( FAO, por sus siglas en inglés). Casos ejemplares en Chile, Costa Rica, Guatemala y Uruguay. Santiago de Chile: FAO, por sus siglas en inglés; 2016. Disponible en: http://www.fao.org/3/ai6003s.pdf

22. García C, Kanashiro M, Sist P. Manejo sostenible de los bosques tropicales Desafíos para las prácticas de aprovechamiento de impacto reducido. Rec. Nat. y Amb [Internet]. 2006-2007 [Consultado 2020 febr. 26];4950:12-17. Disponible en: http://repositorio.bibliotecaorton.catie.ac.cr/bitstream/handle/11554/7348/ RRNA_49-50_Completo.pdf?sequence=1\&isAllowe$\mathrm{d}=\mathrm{y}$

23. Movimiento Mundial por los Bosques Tropicales (WRM, por su sigla en inglés). Conceptos que matan los bosques. Boletín 247 del WrM: nov-dic. 2019. Disponible en: https://wRM.org.uy/es/articulos-del-boletin-wRM/ seccion1/una-lista-incompleta-de-conceptos-que-matan-los-bosques/

24. Jiménez, A, Mantilla, M. El papel de la tala selectiva en la conservación de bosques neotropicales y la utilidad de los murciélagos como bioindicadores de disturbio. Revista Institucional de la Universidad Tecnológica del Chocó: Investigación, Biodiversidad y Desarrollo; 27(1)100-108. Disponible en: https://dialnet.unirioja. es/descarga/articulo/2705046.pdf

25. Armenteras D, González TM, Retana J, Espelta JM, editores. Degradación de bosques en Latinoamérica: Síntesis conceptual, metodologías de evaluación y casos de estudio nacionales. [Lugar no especificado]. RED cyted para el monitoreo del estado de la conservación y recuperación de bosques húmedos y secos en Latinoamérica en el contexto de la deforestación evitada; 2016. Disponible en: http://www.cyted.org/ sites/default/files/Degradacion\%20de\%20bosques\%20 en\%20latinoamerica.pdf

26. Pérez CJ, Locatelli B, Vignola R, Imbach P. Importancia de los bosques tropicales en las políticas de adaptación al cambio climático. Rec. Nat. y Amb [Internet]. 2007 [revisión 2020 febr. 26]; 51:6-13. Disponible en: https:// 
www.researchgate.net/publication/237483950_Importancia_de_los_bosques_tropicales_en_las_politicas_de_adaptacion_al_cambio_climatico

27. Dourojeanni MR. Ocho errores capitales de la gestión forestal en el Perú [Internet]. Lima: SPDA Actualidad Ambiental; 2018 sept. 19 [revisión 2020 febr. 25]. Disponible en: http://www.actualidadambiental. $\mathrm{pe} / \mathrm{p}=52065$

28. Secretaría del Convenio sobre la Diversidad Biológica (scDB). La Diversidad Biológica Forestal. El Tesoro viviente de la Tierra. Montreal: Secretaría del Convenio sobre la Diversidad Biológica; 2010. Disponible en: https://www.cbd.int/idb/doc/2011/idb-2011-booklet-es. pdf

29. Lecaros JA. La ética medio ambiental: principios y valores para una ciudadanía responsable en la sociedad global. Act. Bioethica [Internet]. 2013 [revisión 2020 febr. 26]; 19(2):177-188. Disponible en: DoI: https://doi. org/10.4067/S1726-569X2013000200002

30. Sarmiento PJ. Bioética ambiental y ecopedagogía: una tarea pendiente. Act. Bioethica [Internet]. 2013 [revisión 2020 febr, 26]; 19(1):29-38. Disponible en: DoI: https://doi.org/10.4067/S1726-569X2013000100004

31. Macqueen D. Apelación ética. International Institute Environment and Development (IIED) . 2005. Disponible en: https://policy-powertools.org/Tools/Engaging/ docs/ethical_appeal_tool_spanish.pdf

32. Landínez AY. Apropiación del recurso forestal en la amazonia colombiana: una mirada desde la bioética. rev.latinoam.bioet [Internet]. 2012 [revisión 2020 febr. 26];7(1). Disponible en: DoI: https://doi.org/10.18270/ rcb.v7i1.802

33. Defensoría del Pueblo. La Política Forestal y la Amazonía Peruana: Avances y obstáculos en el camino hacia la sostenibilidad. Serie Informes Defensoriales - Informe No 151. Lima: Defensoría del Pueblo; 2010.

34. Servicio Nacional Forestal y de Fauna Silvestre (sErfor). Política Nacional Forestal y de Fauna Silvestre. Edición de bolsillo. Lima: SERFOR; 2017. 84 p.

35. Servicio Nacional Forestal y de Fauna Silvestre (SERFOR). Ley Forestal y de Fauna Silvestre Ley No 29763 y sus Reglamentos: bosques productivos para la vida. Lima: SERFOR; 2015. 345 p.

36. Arce R. Tratamiento de la ética en las estrategias y planes nacionales ambientales del Perú. Servindi [Internet]. 2020 [revisión 2020 febr, 1]. Disponible en: https:// www.servindi.org/actualidad-opinion/21/01/2020/ tratamiento-de-la-etica-en-las-estrategias-y-planes-nacionales
37. Brand U, Domínguez R, Wissen M, Caria S, Puyana A, Cálix A, Mora H. Más allá del PIB hay vida: una crítica a los patrones de acumulación y estilos de desarrollo en América Latina. Ciudad de México: Friedrich-Ebert-Stiftung. Proyecto Regional Transformación Social-Ecológica; 2018. Disponible en: http://library.fes.de/pdf-files/bueros/ mexiko/14962-20190222.pdf

38. Castro A. Consideraciones éticas para una mirada comprehensiva de la naturaleza. Rev. Kawsaypacha. [PDF] 2017;1:49-68.

39. Polo MA. Ética. Modo de vida, comunidad y ecología. Lima: Editorial Mantaro; 2001.

40. Soria C, Summers P. Limitaciones para la comprensión de los socioecosistemas y su inserción en las políticas públicas. En: Sabogal A, editora. Bosques y cambio climático en el Perú. Lima: Pontificia Universidad Católica del Perú. Instituto de Ciencias de la Naturaleza, Territorio y Energías Renovables (INTE-PUCP); 2017. p. 23-48. Disponible en: http://repositorio.pucp.edu.pe/ index/bitstream/handle/123456789/134554/Nro_7_ Sabogal_Bosques\%20y\%20cambio\%20climatico.pd$\mathrm{f}$ ? sequence $=1$ \&isAllowed $=\mathrm{y}$

41. Cálix A. Los enfoques de desarrollo en América Latina: Hacia una transformación social-ecológica. En: Brand U, Domínguez R, Wissen M, Caria S, Puyana A, Cálix A, Mora H. Más allá del PIB hay vida: una crítica a los patrones de acumulación y estilos de desarrollo en América Latina. Ciudad de México: Friedrich-Ebert-Stiftung. Proyecto Regional Transformación Social-Ecológica; 2018. p. 163-216. Disponible en: http://library.fes.de/pdf-files/bueros/ mexiko/14962-20190222.pdf

42. Machado H. "América Latina” y la ecología política del sur. Luchas de re-existencia, revolución epistémica y migración civilizatoria. En: Alimonda H, ET AL. Ecología política latinoamericana: pensamiento crítico, diferencia latinoamericana y rearticulación epistémica. Volumen II. Ciudad Autónoma de Buenos Aires: CLACSO; México: Universidad Autónoma Metropolitana; Ciudad Autónoma de Buenos Aires: Ciccus; 2017. p. 193-224.

43. Pérez AM. Bioética y Medio Ambiente. El gran desafío del siglo XXI. Cuadernos de Bioética [Internet]. 2000 [revisión 2020 febr. 26]; Disponible en: http://aebioetica.org/revistas/2000/2/42/177.pdf

44. Giménez AM. El desafío de la educación superior en las ciencias forestales. Quebracho Rev. Cs. For [Internet]. 2017 [revisión 2020 febr. 26]; 25(1-2):177183. Disponible en: https://www.redalyc.org/jatsRepo/481/48156296015/html/index.html 
45. Dawkins M. Animal welfare and the paradox of animal consciousness. In Naguib M, Barrett L, editors. Advances in the Study of Behavior. United States. UK: Elsevier Inc;2015; p. 5-38. Avaible from: DoI: https:// doi.org/10.1016/bs.asb.2014.11.001

46. Fernández L. ¿Máquinas biotecnológicas o seres sintientes? Una aproximación antiespecista a la clonación de animales no humanos. Rev. Bio y Der [Internet] 2019 (47):141-157. Disponible en: http://scielo.isciii.es/scielo. php?script=sci_arttext\&pid=S1886-58872019000300011

47. Marín C, Céspedes C. Compuestos volátiles de plantas. Origen, emisión, efectos, análisis y aplicaciones al agro. Rev. Fitotec. Mex. 2007; 30:327-351. Disponible en: https://www.revistafitotecniamexicana.org/documentos/30-4/1r.pdf

48. Mancuso S, Viola A. Sensibilidad e inteligencia en el mundo vegetal. Barcelona: Galaxia Gutenberg; 2013.

49. Ares, R. La conducta de las plantas: etología botánica. Ciudad Autónoma de Buenos Aires: Fundación de Historia Natural Félix de Azara; 2019. 384 p. Disponible en: https://0b3f2d83-44ab-47f9-b2a5-fafabd18d1d5. filesusr.com/ugd/5c1156_70209b4537f54756884e00cd0c2f34c6.pdf

50. Maldonado CE. Las ciencias de la complejidad son las ciencias de la vida. En: Marcos A. Villegas M, Caballero L, Vizcaya E, editores. Biocomplejidad: facetas y tendencias. México: CopIt-arXives; 2019. p. 259-277.

51. Marcos A. Biocomplejidad. En: Villegas M, Caballero, L, Vizcaya E, editores. Biocomplejidad: facetas y tendencias. México: CopIt-arXives; 2019. p. 1-14.

52. Vanegas JH, Duque JE. El hechizo de la conciencia: entre la filosofía y la neurobiología. Arch Med. 2016; 16(2):508-22. Disponible en: DoI: https://doi. org/10.30554/archmed.16.2.1729.2016

53. Rúa JC. Liberar un ruiseñor: una teoría de los derechos para los animales desde el enfoque abolicionista. Opinión Jurídica, 2016; 15(30):205-226. Disponible en: DOI: https://doi.org/10.22395/ojum.v15n30a10

54. Escobar A. Sentipensar con la tierra: nuevas lecturas sobre desarrollo, territorio y diferencia. Medellín: Ediciones Unaula; 2014. 184 p.

55. García R. Sistemas complejos: conceptos, método y fundamentación epistemológica de la investigación interdisciplinaria. Barcelona: Editorial Gedisa; 2006.
56. Velásquez D, Mejía JA. Hacia una epistemología evolutiva extendida: la retroalimentación entre variación y selección. Acta Bio. Colom [Internet]. 2016; 21(3):473480. Disponible en: DoI: https://doi.org/10.15446/abc. v21n3.55630

57. Suárez L, Asunción M; Rivera L. Pratesi I, Galaverni M, Antonelli M. Pérdida de naturaleza y pandemias. Un planeta sano por la salud de la humanidad. Madrid: wWF España; 2020. 16 p. 